УДК 316.346.32-053.9:314

\title{
РЕАЛИЗАЦИЯ ПОТЕНЦИАЛА СТАРШЕГО ПОКОЛЕНИЯ. ДЕМОГРАФИЧЕСКИЕ ПРОЦЕССЫ
}

\author{
Монастырный Евгений Александрович1,2, \\ e.monastyrny@gmail.com \\ Касинский Сергей Викторович ${ }^{3}$, \\ P70_mail@gks.ru \\ Дырко Нина Петровна3, \\ P70_mail@gks.ru \\ Котова Валентина Викторовна ${ }^{3}$, \\ P70_mail@gks.ru
}
${ }^{1}$ Национальный исследовательский Томсий политехнический университет, Россия, 634050, г. Томск, пр. Ленина, 30.
2 Томский научный центр СО РАН, Россия, 634055, г. Томск, пр. Академический, 10/4.
3 Федеральная служба государственной статистики по Томской области, Россия, 634050, г. Томск, ул. Гагарина, 56.

\begin{abstract}
Монастырный Евгений Александрович, доктор экономических наук, ведущий научный сотрудник Международной научно-образовательной лаборатории технологий улучшения благополучия пожилых людей Национального исследовательского Томского политехнического университета; заведующий лабораторией устойчивого развития социально-экономических систем Томского научного центра СО РАН.
\end{abstract}

Касинский Сергей Викторович, руководитель территориального органа Федеральной службы государственной статистики по Томской области.

Дырко Нина Петровна, заместитель руководителя территориального органа Федеральной службы государственной статистики по Томской области.

Котова Валентина Викторовна, главный специалист-эксперт отдела сводных статистических работ территориального органа Федеральной службы государственной статистики по Томской области.

Актуальность работы определяется глобальными процессами: старением населения в целом, вызванным снижением рождаемости и ростом продолжительности жизни, и увеличением экономически активного возраста. Явление старения человечества и процесс жизнедеятельности людей старших возрастных групп развиваются в сложном слабоструктурированном проблемном поле и относятся к классу «мягких» систем. Одной из важнейших проблем исследования подобного класса явлений является вовлечение в научный оборот необходимого объема эмпирической информации. Данная работа открывает цикл статей, посвященных вопросам сбора и анализа статистической информации о процессах реализации потенциала старшего поколения в Российской Федерации на примере Томской области. Цель исследования: оценить характеристики выборки лиц старших возрастных групп и пенсионеров по старости по статистическим данным Росстата и Пенсионного фонда РФ по Томской области с позиций подготовки информации для принятия управленческих решений. Источниками информации являются Росстат, Единая межведомственная информационностатистическая систем (ЕМИСС), Томскстат, информация, получаемая по согласованным запро- 
сам в территориальный орган статистики, результаты социологических исследований. Методы: подходы описательной статистики (сравнения, отношения, визуализация динамики изменений, статистический анализ). Логика, структура и методы анализа материала соответствуют принятым в официальных статистических обзорах и аналитических записках. Анализ статистических форм и оценка их доступности в региональном разрезе позволили выбрать для дальнейшего исследования основные источники информации. Проведены детальный анализ демографических процессов в старших возрастных группах населения Томской области и сравнение регионов Сибирского федерального округа по некоторым показателям. Приводится возрастно-половая структура населения Томской области старше трудоспособного возраста, показатели смертности населения старше трудоспособного возраста по основным классам причин смерти. Данные статистики подтверждают факт, что процесс старения населения региона будет продолжаться. В работе анонсированы две следующие статьи единого цикла - «Реализация потенциала старшего поколения. Уровень жизни» и «Реализация потенциала старшего поколения. Участие на рынке труда».

Ключевые слова: Демографические процессы, реализация потенциала, работающие пенсионеры, старшие возрастные группы, реформа пенсионной системы.

Настоящая работа открывает цикл статей, посвященных вопросам сбора и анализа статистической информации о процессах реализации потенциала старшего поколения в Российской Федерации на примере Томской области. Актуальность проблемы определяется глобальными процессами: старением населения в целом, вызванным снижением рождаемости и ростом продолжительности жизни, увеличением экономически активного возраста. Первая проблема нашла широкое отражение в научной литературе последних десятилетий [1-5], вторая же оказалась в тени, но ее значимость значительно возросла в последнее время [6-9].

Явление старения человечества и процесс жизнедеятельности людей старших возрастных групп как социально-экономические и психолого-физиологические феномены развиваются в сложном слабоструктурированном проблемном поле и относятся к классу «мягких» систем, что требует от исследователей использования подходов «мягкого» системного анализа [10-13].

Множественность проблем, неочевидность методов их решения приводят к необходимости построения комплексной модели «мягких» систем как согласованной совокупности моделей разного уровня обобщения и различного целеполагания [14].

Одной из важнейших проблем исследования подобного класса явлений и разработки комплексных моделей является вовлечение в научный оборот необходимого объема эмпирической информации. Источниками такой информации являются статистическое наблюдение (текущее или прерывное, сплошное или выборочное), социологические обследования и экспертные заключения $[6,15,16]$.

\section{Цель исследования}

Оценка характеристики выборки лиц старших возрастных групп и пенсионеров по старости по статистическим данным Росстата и Пенсионного фонда РФ по Томской области с позиций подготовки информации для принятия управленческих решений.

\section{Задачи}

1. Провести анализ статистических форм и выбрать основные источники информации для дальнейшего исследования по направления «Демографические процессы», «Уровень жизни», «Участие на рынке труда людей старших возрастных групп».

2. Исследовать демографические процессы в старших возрастных группах.

3. Оценить уровень жизни лиц старшего поколения. 
4. Исследовать уровень участия на рынке труда людей старших возрастных групп.

5. Разработать на основе анализа статистической информации модель процессов реализации потенциала старшего поколения.

В статье авторы решают первые две из поставленных задач:

- проводят анализ статистических форм и выбирают основные источники информации для дальнейшего исследования;

- исследуют демографические процессы в старших возрастных группах.

\section{Источники информации}

Источниками информации являются Росстат [17, 18], Единая межведомственная информационно-статистическая систем (ЕМИСС) [19], Томскстат [20], аналитические записки Томскстата [21-23], информация, получаемая по согласованным запросам в территориальный орган статистики, результаты социологических исследований. Дополнительные источники информации приводятся в работе «Социально-экономическая статистика благополучия старшего поколения» [24].

\section{Методология}

В работе используются подходы описательной статистики: сравнения, отношения, визуализация динамики изменений, статистический анализ. Логика, структура и методы анализа материала соответствуют принятым в официальных статистических обзорах и аналитических записках. Такой подход наиболее удобен для представления больших объемов информации и привычен для лиц, использующих информацию для принятия управленческих решений.

\section{Выбор основных источников информации}

В ходе выполнения научно-исследовательских работ авторами ранее были выявлены более 30 статистических форм Росстата и других министерств и ведомств РФ, содержащих более 150 показателей, характеризующих выборки лиц старших возрастных групп и пенсионеров по старости.

Анализ этих форм и оценка их доступности в региональном разрезе позволили выбрать для дальнейшего исследования основные источники информации.

Демографические оценки проводились на основе итогов последней переписи населения и текущего учета демографических событий.

К ним относятся формы статистического наблюдения «Сведения об умерших», «Сведения о родившихся», сведения о лицах, прибывших в муниципальное образование и зарегистрированных в нем по месту жительства в территориальных органах Федеральной миграционной службы (ФМС) России в течение отчетного года, сведения о лицах, выбывших из муниципального образования и снявшихся с регистрационного учета в территориальных органах ФМС России в течение отчетного года.

Для оценки уровня жизни людей старших возрастных групп использовались следующие статистические формы:

- Сведения о численности пенсионеров и суммах назначенных им пенсий.

- Сведения о величине прожиточного минимума, установленной в субъекте Российской Федерации.

- Сведения о реализации мер социальной поддержки отдельных категорий граждан за счет средств консолидированного бюджета субъекта Российской Федерации. 
- Сведения о средствах на реализацию мер социальной поддержки отдельных категорий граждан по расходным обязательствам субъекта Российской Федерации и муниципальных образований.

- Сведения о поступлении и расходовании средств Фонда социального страхования Российской Федерации.

- Сведения о поступлении и расходовании средств Пенсионного фонда Российской Федерации.

- Выборочное обследование бюджетов домашних хозяйств. Опросный лист для обследования бюджетов домашних хозяйств.

- Комплексное наблюдение условий жизни населения. Вопросник для домохозяйства. Индивидуальный вопросник для лиц в возрасте 15 лет и более.

Исследование уровня участия на рынке труда людей старших возрастных групп проводилось с использованием информации следующих статистических форм:

- выборочное наблюдение доходов населения и участия в социальных программах; вопросник для домохозяйства; индивидуальный вопросник для лиц в возрасте 16 лет и более;

- выборочное обследование рабочей силы; анкета выборочного обследования рабочей силы;

- выборочное обследование организаций (без предприятий, относящихся к субъектам малого предпринимательства и без организаций с численностью менее 15 человек), сведения о средней начисленной заработной плате и численности работников по группам занятий, возрастным группам и полу. Форма: Сведения о заработной плате работников по профессиям и должностям.

Необходимо отметить, что в отдельных статистических формах присутствовали показатели, используемые в различных направлениях исследования. Это, в первую очередь, относится к форме 94 (ПЕНСИИ) «Сведения о численности пенсионеров и суммах назначенных им пенсий», и Комплексному наблюдению условий жизни населения (КОУЖ).

\section{Демографические процессы}

Данный раздел статьи выстроен в логике и с использованием материалов [21-23]. В Томской области, как и по России в целом, наблюдается процесс демографического старения населения. С 2010 по 2018 гг. отмечался устойчивой рост численности населения старше трудоспособного возраста, опережающий рост всего населения Томской области. Так, если численность жителей области за этот период увеличилась на 2,8 \%, то населения старше трудоспособного возраста - на 21,9 \%. Численность населения в трудоспособном возрасте снизилась на 7,0 \% (табл. 1).

В табл. 2, 3 приведены данные по субъектам Сибирского федерального округа РФ о доле населения старше трудоспособного возраста и ожидаемой продолжительности жизни лиц старшего возраста.

Увеличение численности населения старших возрастов отмечалось во всех возрастных группах, кроме 70-74 лет. Так, численность населения в возрастной группе 60-64 года возросла за эти годы на 13,8 тыс. чел. $(24,5 \%)$. В возрастной группе 65-69 лет наблюдался еще более значительный рост численности населения - абсолютный прирост составил 31,6 тыс. чел., относительный - 2,3 раза.

Стабильно увеличивалась ожидаемая продолжительность жизни мужчин и женщин. В 2018 г. она составила 72,8 года (в 2010 г. - 68,8 года), в том числе мужчин 67,7 года $(63,1)$, женщин - 77,8 года $(74,8)$ (табл. 4). Снизилась смертность населения 
по всем возрастным группам - с 12,6 на 1000 человек населения в 2010 г. до 11,1 в 2018 г., в том числе населения старше трудоспособного возраста - с 44 до 37 на 1000 человек населения данной возрастной категории.

Таблица 1. Возрастной состав населения Томской области на начало года, тыс. чел. Table 1. Age composition of population of the Tomsk region at the beginning of the year, thousand people

\begin{tabular}{|l|c|c|c|c|c|c|}
\hline Показатели/Indicators & 2011 & 2015 & 2016 & 2017 & 2018 & 2019 \\
\hline $\begin{array}{l}\text { Все население } \\
\text { The entire population }\end{array}$ & 1048,5 & 1074,5 & 1076,8 & 1078,9 & 1078,3 & 1077,4 \\
\hline в том числе/including: \\
\hline $\begin{array}{l}\text { моложе трудоспособного возраста } \\
\text { уоunger than working age }\end{array}$ & 176,1 & 194,6 & 199,1 & 202,9 & 205,5 & 206,4 \\
\hline $\begin{array}{l}\text { в трудоспособном возрасте } \\
\text { at working age }\end{array}$ & 665,8 & 649,1 & 640,6 & 633,8 & 625,9 & 619,2 \\
\hline $\begin{array}{l}\text { старше трудоспособного возраста } \\
\text { older than working age }\end{array}$ & 206,6 & 230,7 & 237,1 & 242,3 & 246,9 & 251,8 \\
\hline
\end{tabular}

${ }^{1}$ Мужчины в возрасте 60 лет и более, женщины - 55 лет и более/Men aged 60 years and over, women aged 55 years and over.

Таблица 2. Население по субъектам Сибирского федерального округа РФ в возрасте старше трудоспособного в \% ко всему населению (на начало года)

Table 2. Population by constituent entities of the Siberian Federal District of the Russian Federation older than able-bodied in \% of the total population (at the beginning of the year)

\begin{tabular}{|c|c|c|c|c|c|c|c|}
\hline Показатели/Indicators & 2012 & 2013 & 2014 & 2015 & 2016 & 2017 & 2018 \\
\hline $\begin{array}{l}\text { Российская Федерация } \\
\text { Russian Federation }\end{array}$ & 22,7 & 23,1 & 23,5 & 24,0 & 24,6 & 25,0 & 25,4 \\
\hline $\begin{array}{l}\text { Сибирский федеральный округ } \\
\text { Siberian Federal District }\end{array}$ & 20,9 & 21,3 & 21,8 & 22,4 & 22,9 & 23,4 & 23,8 \\
\hline $\begin{array}{l}\text { Республика Алтай } \\
\text { Republic of Altai }\end{array}$ & 15,4 & 15,8 & 16,3 & 16,8 & 17,3 & 17,9 & 18,5 \\
\hline $\begin{array}{l}\text { Pеспублика Тыва } \\
\text { Republic of Tuva }\end{array}$ & 9,9 & 10,1 & 10,3 & 10,6 & 10,9 & 11,1 & 11,4 \\
\hline $\begin{array}{l}\text { Республика Хакасия } \\
\text { Republic of Khakassia }\end{array}$ & 20,3 & 20,9 & 21,4 & 21,9 & 22,5 & 22,9 & 23,4 \\
\hline $\begin{array}{l}\text { Алтайский край } \\
\text { Altai Region }\end{array}$ & 23,5 & 24,1 & 24,7 & 25,3 & 26,0 & 26,6 & 27,2 \\
\hline $\begin{array}{l}\text { Красноярский край } \\
\text { Krasnoyarsk region }\end{array}$ & 20,3 & 20,7 & 21,1 & 21,6 & 22,1 & 22,5 & 23,0 \\
\hline $\begin{array}{l}\text { Иркутская область } \\
\text { Irkutsk region }\end{array}$ & 20,1 & 20,6 & 21,1 & 21,6 & 22,0 & 22,4 & 22,8 \\
\hline $\begin{array}{l}\text { Кемеровская область } \\
\text { Kemerovo region }\end{array}$ & 22,3 & 22,8 & 23,4 & 24,0 & 24,6 & 25,1 & 25,6 \\
\hline $\begin{array}{l}\text { Новосибирская область } \\
\text { Novosibirsk Region }\end{array}$ & 22,7 & 23,0 & 23,4 & 23,8 & 24,3 & 24,7 & 25,0 \\
\hline $\begin{array}{l}\text { Омская область } \\
\text { Omsk region }\end{array}$ & 21,6 & 22,1 & 22,6 & 23,2 & 23,8 & 24,4 & 25,0 \\
\hline $\begin{array}{l}\text { Томская область } \\
\text { Tomsk region }\end{array}$ & 20,1 & 20,5 & 21,0 & 21,5 & 22,0 & 22,5 & 22,9 \\
\hline
\end{tabular}


Таблица 3. Ожидаемая продолжительность жизни лиц старшего возраста по субъектам Сибирского федерального округа РФ (для мужчин, достигших 60 лет, и женщин, достигших 55 лет)

Table 3. Life expectancy of older persons in the subjects of the Siberian Federal District of the Russian Federation (for men over 60 years old and women over 55 years old)

\begin{tabular}{|c|c|c|c|c|c|c|c|c|c|c|c|c|}
\hline \multirow{2}{*}{$\begin{array}{c}\text { Показатели } \\
\text { Indicators }\end{array}$} & \multicolumn{2}{|c|}{2013} & \multicolumn{2}{|c|}{2014} & \multicolumn{2}{|c|}{2015} & \multicolumn{2}{|c|}{2016} & \multicolumn{2}{|c|}{2017} & \multicolumn{2}{|c|}{2018} \\
\hline & $\mathrm{M}$ & Ж & $\mathrm{M}$ & Ж & $\mathrm{M}$ & Ж & $\mathrm{M}$ & Ж & $\mathrm{M}$ & Ж & $\mathrm{M}$ & Ж \\
\hline сийск & 15,7 & 25,4 & 15,9 & 25,5 & 16,0 & 25,6 & 16,1 & 25,8 & 16,5 & 26,1 & 16,6 & 26,3 \\
\hline $\begin{array}{l}\text { Сибирский } \\
\text { федеральный округ } \\
\text { Siberian Federal } \\
\text { District } \\
\end{array}$ & 14,9 & 24,6 & 15,0 & 24,8 & 15,1 & 24,9 & 15,1 & 25,1 & 15,4 & 25,3 & 15,4 & 25,5 \\
\hline $\begin{array}{l}\text { еспублика Алтай } \\
\text { Republic of Altai }\end{array}$ & 14,1 & 24,4 & 14,5 & 24,4 & 14,5 & 24,5 & 15,2 & 24,9 & 15,8 & 25,2 & 14,9 & 25,2 \\
\hline $\begin{array}{l}\text { Республи } \\
\text { Republic }\end{array}$ & 13,1 & 21,0 & 12,6 & 21,2 & 13,2 & 21,2 & 13,3 & 21,6 & 14,4 & 22,8 & 13,6 & 22,3 \\
\hline еспубли & 14,7 & 24,1 & 4,5 & 24,4 & 4,7 & 24,1 & 15,1 & 24,6 & 15,0 & 24,8 & 15,4 & 25,1 \\
\hline $\begin{array}{l}\text { Алтайски } \\
\text { Altai Regi }\end{array}$ & 15,2 & 25,0 & 15,0 & 25,1 & 15,5 & 25,1 &, 2 & 25,4 &, 5 & ,5 & 15,6 & 25,6 \\
\hline $\begin{array}{l}\text { Сраснояр } \\
\text { Krasnoyar }\end{array}$ & 14,8 & 24,6 & 14,8 & 24,7 & 15,0 & 24,8 & 15,1 & 25,2 & 15,4 & 25,3 & 15,2 & 25,5 \\
\hline $\begin{array}{l}\text { Хркутск: } \\
\text { rkutsk re }\end{array}$ & 14,3 & 24,4 & 14,5 & 24,4 & 14,7 & 24,4 & 14,5 & 24,7 & 14,8 & 25,1 & 14,8 & 25,1 \\
\hline Кемеровс & 14,8 & 24,5 & 14,8 & 24,6 & 14,9 & 24,8 & 15,0 & 24,8 & 15,2 & 25,1 & 15,3 & 25,1 \\
\hline $\begin{array}{l}\text { Новосибирская } \\
\text { область } \\
\text { Novosibirsk Region }\end{array}$ & 15,3 & 25,2 & 15,5 & 25,4 & 15,6 & 25,7 & 15,5 & 25,8 & 15,9 & 26,0 & 15,7 & 26,0 \\
\hline . & 15,1 & 24,8 & 15,2 & 25,2 & 15,2 & 25,2 & 15,2 & 25,4 & 15,6 & 25,6 & 15,6 & 25,9 \\
\hline $\begin{array}{l}\text { Томская область } \\
\text { Tomsk region }\end{array}$ & 15,6 & 25,1 & 15,7 & 25,4 & 16,1 & 25,4 & 15,9 & 25,8 & 16,2 & 25,8 & 16,4 & 26,2 \\
\hline
\end{tabular}

Таблица 4. Ожидаемая продолжительность жизни при рождении, лет Table 4. Life expectancy at birth, years

\begin{tabular}{|c|c|c|c|}
\hline Годы/Years & Всего/Total & Мужчины/Men & Женщины/Women \\
\hline 2010 & 68,8 & 63,1 & 74,8 \\
\hline 2013 & 70,3 & 64,8 & 75,9 \\
\hline 2014 & 70,7 & 64,9 & 76,5 \\
\hline 2015 & 71,3 & 65,9 & 76,5 \\
\hline 2016 & 71,7 & 66,2 & 77,1 \\
\hline 2017 & 72,0 & 66,6 & 77,3 \\
\hline 2018 & 72,8 & 67,7 & 77,8 \\
\hline
\end{tabular}

В Томской области на начало 2019 г. насчитывалось 251,8 тыс. чел. старше трудоспособного возраста. Доля старшего поколения в общей численности населения выросла с 19,7 \% на начало 2011 г. до 23,4 \% на начало 2019 г. (табл. 5). Отметим, что доля населения в возрасте старше трудоспособного во всем населении в целом по России составляла на начало 2010 г. 21,8 \%, 2019 г. - 25,9\%. 


\section{Таблица 5. Численность населения старше трудоспособного возраста на 1 января, тыс. чел.}

Table 5. Population over the working age as of January 1, thousand people

\begin{tabular}{|l|c|c|c|c|c|c|}
\hline \multicolumn{1}{|c|}{ Показатели/Indicators } & 2011 & 2015 & 2016 & 2017 & 2018 & 2019 \\
\hline $\begin{array}{l}\text { Численность населения старше } \\
\text { трудоспособного возраста - всего } \\
\begin{array}{l}\text { Population older than able-bodied } \\
\text { ages - Total }\end{array}\end{array}$ & 206,6 & 230,7 & 237,1 & 242,3 & 246,9 & 251,8 \\
\hline Мужчин/Men & 59,7 & 68,1 & 70,5 & 72,7 & 75,0 & 77,7 \\
\hline Женщин/Women & 146,9 & 162,6 & 166,6 & 169,6 & 171,9 & 174,1 \\
\hline $\begin{array}{l}\text { Доля численности населения старше } \\
\text { трудоспособного, \% } \\
\begin{array}{l}\text { Proportion of population older than working age } \\
\text { in the entire population, \% }\end{array}\end{array}$ & 19,7 & 21,5 & 22,0 & 22,5 & 22,9 & 23,4 \\
\hline
\end{tabular}

Процесс демографического старения в большей степени характерен для женщин. На начало 2019 г. в составе населения старше трудоспособного возраста женщины составляли 69,1\%. Это связано с тем, что продолжительность жизни женщин на 10 лет больше, чем у мужчин. Кроме того, пенсионный возраст женщин наступал с 55 лет, т. е. на 5 лет раньше.

Преобладание численности женщин в возрасте старше трудоспособного над численностью мужчин данной категории достаточно существенное, хотя в последние годы диспропорция полов немного уменьшилась: на начало 2011 г. на 1000 мужчин приходилось 2460 женщин, на начало 2015 г. - 2386, на начало 2019 г. - 2240.

Диспропорция полов во всех старших возрастных группах весьма заметна, и чем старше возрастная группа, тем более она выражена. Если в возрасте 60-64 лет женщин в 1,4 раза больше, чем мужчин, то в возрасте 75-79 лет - в 2,2 раза, а в возрасте 85 лет и более - в 3,3 раза (рис. 1).

Значительное влияние на соотношение полов старшего поколения оказывает высокая смертность мужчин. В 2018 г. уровень смертности мужчин в возрасте 60 лет и более в 1,7 раза превышал уровень смертности женщин в возрасте 55 лет и более. Если среди мужчин на 1000 человек пенсионного возраста и старше приходилось 52 умерших, то среди женщин - 30 .

В 2018 г. в возрасте старше трудоспособного умерло 9034 человека (табл. 6).

Основной причиной смертности остаются болезни системы кровообращения (БСК) - от них умерло около половины (48,9 \%) населения старше трудоспособного возраста. Второе место заняли новообразования - каждый пятый умер от этой группы заболеваний. Далее с заметным отрывом от БСК и новообразований следовали болезни органов пищеварения (6,9 \%) и внешние причины (4,9\%). По сравнению с 2010 г. люди старшего возраста реже умирали от болезней системы кровообращения, а от новообразований и болезней органов пищеварения - чаще (рис. 2).

На сегодняшний день, согласно международным критериям, население Томской области является старым, т. к. возрастной порог в 65 лет переступило более 7,0 \% жителей. Удельный вес лиц в возрасте 65 лет и более на начало 2019 г. составил 13,2\%.

Процесс старения населения будет продолжаться. По прогнозным данным доля лиц старше трудоспособного возраста к 2036 г. увеличится в Томской области до $27,1 \%$, а доля населения в трудоспособном возрасте сократится до 56,0 \% (на начало 2019 г. $-57,5 \%)$. 

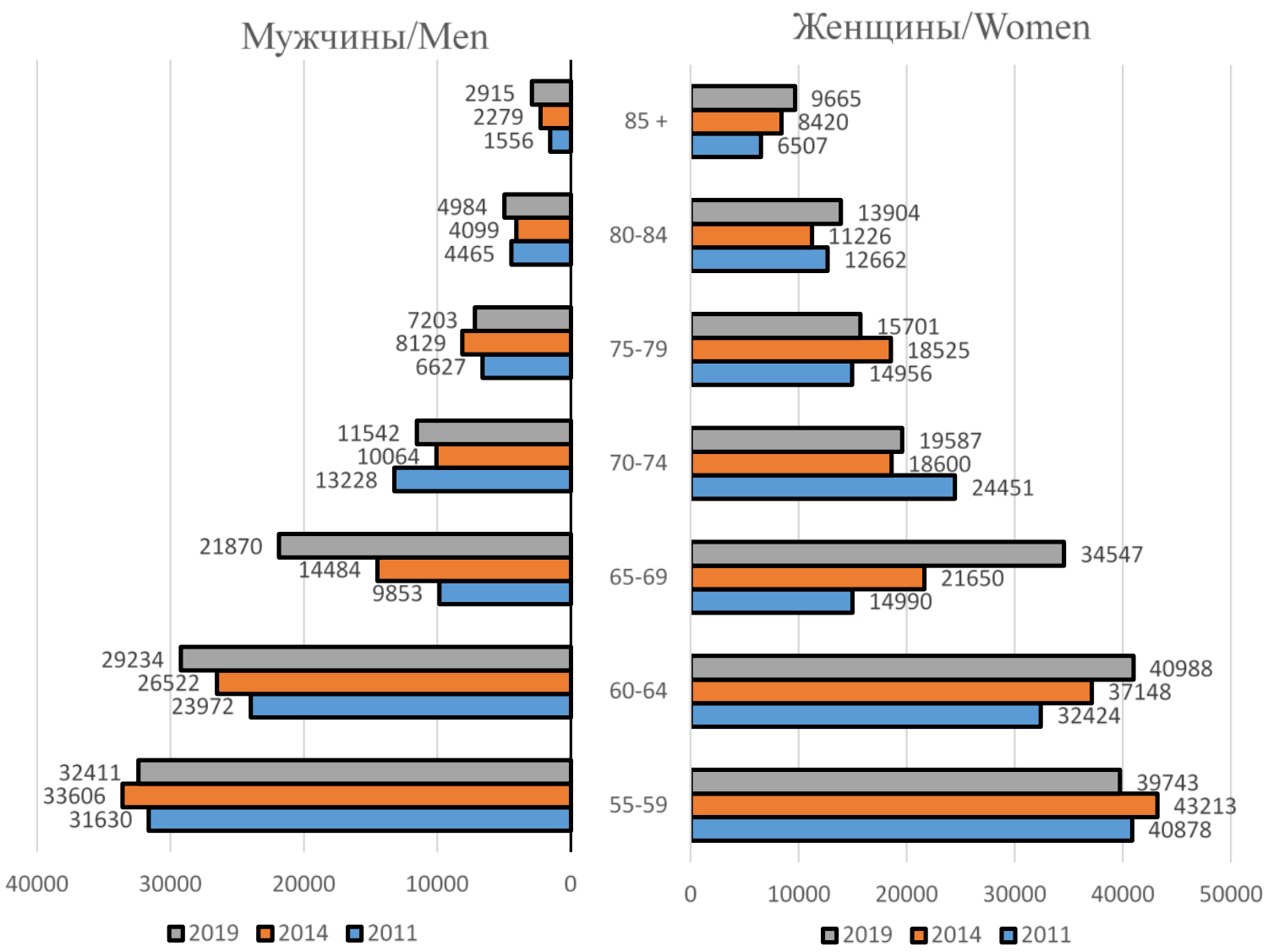

Рис. 1. Возрастно-половая структура населения старше трудоспособного возраста (на начало года), чел.

Fig. 1. Age and sex structure of the population older than working age (at the beginning of the year)

Таблица 6. Смертность населения старше трудоспособного возраста по основным классам причин смерти, чел.

Table 6. Mortality rate of population older than working age by main classes of causes of death, persons

\begin{tabular}{|c|c|c|c|c|c|c|}
\hline Показатели/Indicators & 2010 & 2014 & 2015 & 2016 & 2017 & 2018 \\
\hline Всего умерших/Died of all causes & 8851 & 8779 & 8812 & 8880 & 9076 & 9034 \\
\hline \multicolumn{7}{|l|}{ из них/including: } \\
\hline $\begin{array}{l}\text { от некоторых инфекционных и паразитарных болезней } \\
\text { infectious and parasitic diseases }\end{array}$ & 49 & 99 & 44 & 64 & 55 & 90 \\
\hline от новообразований/neoplasms & 1620 & 1714 & 1802 & 1703 & 1887 & 1835 \\
\hline $\begin{array}{l}\text { от болезней системы кровообращения } \\
\text { circulatory diseases }\end{array}$ & 5144 & 4568 & 4535 & 4523 & 4598 & 4422 \\
\hline от болезней органов дыхания/respiratory illnesses & 274 & 480 & 475 & 472 & 403 & 413 \\
\hline от болезней органов пищеварения/digestive diseases & 369 & 479 & 494 & 576 & 544 & 622 \\
\hline от внешних причин смерти/external causes & 442 & 339 & 380 & 364 & 381 & 444 \\
\hline по старости/old age & 480 & 359 & 527 & 473 & 343 & 318 \\
\hline
\end{tabular}

Следует отметить рост в динамике показателя демографической нагрузки, что также свидетельствует о старении населения. В 2010 г. на 1000 человек трудоспособного возраста в регионе приходилось 650 граждан нерабочих возрастов, в 2018 г. - 723. 
2010 r.

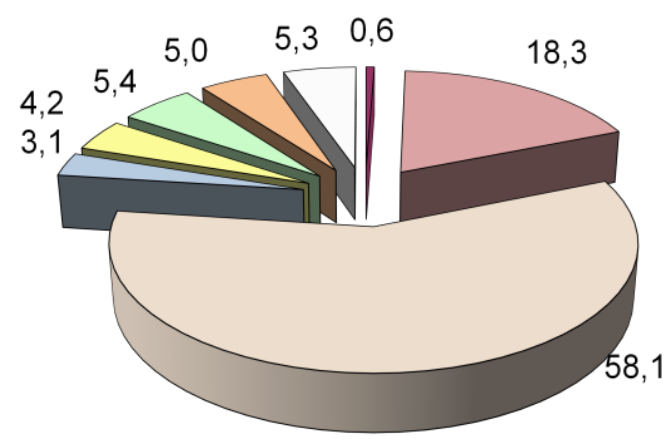

口инфекционные и паразитарные болезни / infectious and parasitic diseases

口болезни системы кровообращения / circulatory diseases

口болезни органов пищеварения / digestive diseases

口внешние причины / external causes
2018 r.

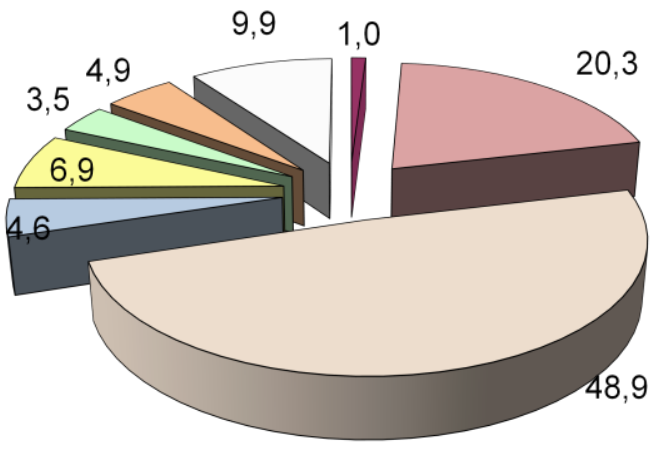

口новообразования / neoplasms

口болезни органов дыхания / respiratory illnesses

口старость / old age

口другие причины / other reasons

Pис. 2. Структура смертности населения старше трудоспособного возраста по основным классам причин смерти, \%

Fig. 2. Structure of mortality of the population older than working age by main classes of causes of death, \%

Следующими статьями заявленного единого цикла работ будут «Реализация потенциала старшего поколения. Уровень жизни» и «Реализация потенциала старшего поколения. Участие на рынке труда».

Исследование выполнено при поддержке РНФ, проект № 19-18-00300 «Институты реализации ресурсного потенциала старшего поколения в экономике старения».

\section{СПИСОК ЛИТЕРАТУРЫ}

1. Gee E., Gutman G. The overselling of population ageing: apocalyptic demography, intergenerational challenges, and social policy. - Oxford: Oxford University Press, 2000. - 192 p.

2. Tinker A. The social implications of an ageing population // Mechanisms of Ageing and Development. 2002. - V. 123. - Iss. 7. - P. 729-735. URL: https://doi.org/10.1016/S0047-6374(01)00418-3 (дата обращения 10.06.2019).

3. Bengtsson T., Scott K. Population aging and the future of the welfare state: the example of Sweden // Population and Development Review. - 2011. - V. 37. - P. 158-170.

4. Lee R. The outlook for population growth // Science. - 2011. - V. 333. - Iss. 6042. - P. 569-573.

5. Доброхлеб В.Г. Старение населения России: региональный аспект // Вопросы территориального развития. - 2018. - № 4 (44). DOI: 10.15838/tdi.2018.4.44.4.

6. Старения больше не будет / И.А. Григорьева, И.Л. Сизова, Л.А. Видясова, А.В. Дмитриева, О.А. Парфенова, И.С. Петухова. - СПб.: Астерион, 2018. - 136 с.

7. Palomba R., Kotowska I., Kotowska I.E. The economically active population in Europe. - Strasbourg: Council of Europe, 2003. - 126 p.

8. Вишневская Н.Т. Работники старших возрастов на рынке труда в странах ОЭСР // Экономический журнал Высшей школы экономики. - 2017. - Т. 21. - № 4. - С. 680-701.

9. Проблемы развития активного долголетия: глобальные тенденции и региональные особенности / С.Г. Шульгин, Ю.В. Зинькина, И.А. Алешковский, А.И. Андреев // Вестник Московского университета. Серия 27 «Глобалистика и геополитика». - 2018. - № 4. - С. 55-68. 
10. Rittel H.W. J., Webber M.M. Dilemmas in a general theory of planning // Policy Science. - 1973. - V. 4. P. 155-169.

11. Акофф Р. Планирование будущего корпорации. - М.: Прогресс, 1985. - 327 с.

12. Клейнер Г.Б. «Мягкие» и «жесткие» системы в экономике // Системная экономика, экономическая кибернетика, мягкие измерения: XVII Международная конференция. - СПб.: СПбГЭТУ «ЛЭТИ», 2014. - C. 6-12.

13. Зуб А.Т., Локтионов М.В. Стратегический менеджмент: Системный подход. - М.: Генезис, 2011. $848 \mathrm{c.}$

14. Гуменников И.В., Монастырный Е.А. Комплексное моделирование социально-экономических процессов и систем. Мягкий системный анализ // Информационные технологии в науке, управлении, социальной сфере и медицине: сборник научных трудов V Международной научной конференции. Ч. 2. - Томск: Изд-во ТПУ, 2018. - С. 437-443.

15. Реализация потенциала старшего поколения: статистика занятости (на примере Сибирского федерального округа и Томской области / Е.А. Монастырный, С.В. Касинский, Н.П. Дырко, В.В. Котова // Новые тенденции в деятельности социозащитных институтов: материалы Всероссийской конференции - Иркутск: Изд-во Байкал. гос. ун-та, 2019. - С. 24-29.

16. Монастырный Е.А. Ресурсный потенциал старшего поколения в зеркале официальной статистики на примере Томской области // Информационные технологии в науке, управлении, социальной сфере и медицине: сборник научных трудов VI Международной конференции. - Томск: Изд-во ТПУ, 2019. С. 570-572.

17. Федеральная служба государственной статистики России. URL: https://www.gks.ru/ (дата обращения: 10.05.2019).

18. Старшее поколение // Федеральная служба государственной статистики России. URL: https://www.gks.ru/folder/13877 (дата обращения 10.05.2019).

19. Единая межведомственная информационно-статистическая система. URL: https://fedstat.ru/ (дата обращения 10.05.2019).

20. Территориальный орган Федеральной службы государственной статистики по Томской области. URL: https://tmsk.gks.ru/ (дата обращения 10.05.2019).

21. Старшее поколение Томской области. 2015: Аналитическая записка. - Томск: Томскстат, 2015. $14 \mathrm{c}$.

22. Старшее поколение Томской области. 2016: Аналитическая записка. - Томск: Томскстат, 2016. $14 \mathrm{c}$.

23. Старшее поколение Томской области: демография и участие на рынке труда: Аналитическая записка. - Томск: Томскстат, 2019. - 18 с.

24. Социально-экономическая статистика благополучия старшего поколения / Ф. Касати, Г.А. Барышева, Е.А. Монастырный, Л.И. Иванкина, И.А. Павлова, М.Л. Шинкеев, В.В. Спицын, Н.М. Панькова, И.В. Гуменников. - Томск: Изд-во ТПУ, 2016. - 264 с.

Поступила 13.06. 2019 г. 
UDC 316.346.32-053.9:314

\title{
REALIZATION OF THE POTENTIAL OF THE OLDER GENERATION. DEMOGRAPHIC PROCESSES
}

\author{
Eugeniy A. Monastyrny 1,2 , \\ e.monastyrny@gmail.com \\ Sergey V. Kasinsky3, \\ P70_mail@gks.ru \\ Nina P. Dyrko3, \\ P70_mail@gks.ru \\ Valentina V. Kotova ${ }^{3}$, \\ P70_mail@gks.ru \\ ${ }^{1}$ National Research Tomsk Polytechnic University, \\ 30, Lenin Avenue, Tomsk, 634050, Russia. \\ 2 Tomsk Scientific Center SB RAS, \\ 10/4, Academic Avenue, Tomsk, 634055, Russia. \\ 3 Federal Service for State Statistics for the Tomsk Region, \\ 56, Gagarin Street, Tomsk, 634050, Russia.
}

Eugeniy A. Monastyrny, Dr. Sc., leading research worker, National Research Tomsk Polytechnic University.; head of the laboratory of sustainability of socio-economic systems, Tomsk Scientific Center SB RAS.

Sergey V. Kasinsky, head of the Territorial Body of the Federal Service for State Statistics for the Tomsk Region.

Nina P. Dyrko, deputy head of the Territorial Body of the Federal Service for State Statistics for the Tomsk Region.

Valentina V. Kotova, chief specialist, aggregated statistical efforts department of the Territorial Body of the Federal Service for State Statistics for the Tomsk Region.

The relevance of the work is determined by global processes: ageing of population as a whole, caused by declining fertility and rising longevity and increase in economically active age. The phenomenon of mankind's aging and the process of life activity of older age groups develop in a complex weakly structured problem field and belong to the class of «soft» systems. One of the most important problems in the study of such class of phenomena is the involvement of the necessary amount of empirical information in the scientific circulation. This paper opens a series of articles devoted to collection and analysis of statistical information on realization of the potential of the older generation in the Russian Federation on the example of the Tomsk region. The aim of the research is to evaluate the characteristics of the sample of senior age groups and oldage pensioners according to the statistical data of Rosstat and the Pension Fund of the Russian Federation for the Tomsk region from the point of view of information preparation for making managerial decisions. The sources of information are Rosstat, the Unified Interdepartmental Information and Statistical Systems (EMISS), Tomskstat, information obtained upon agreed requests to the territorial statistical office, and the results of sociological research. Methodology: approaches of descriptive statistics: comparisons, relations, visualization of dynamics of changes, statistical analysis. The logic, structure and methods of analysis of the material correspond to those adopted in official statistical surveys and policy briefs. Analysis of statistical forms and assessment of their availability in regional context allowed selecting the main sources of information for further research. The article provides a detailed analysis of demographic processes in the senior age groups of the Tomsk region and compares the regions of the Siberian Federal District by some indicators. 
The age and sex structure of the population of the Tomsk region is given above the working age, as well as mortality rates of the population above the working age by the main classes of causes of death. Statistical data confirm the fact that the population ageing in the region will continue. The paper introduces the following two articles of the single cycle "Realization of the potential of the older generation. Standard of living» and «Realization of the potential of the older generation. Participation in the labor market».

Key words: Demographic processes, realization of potential, working pensioners, senior age groups, pension system reform.

The research was supported by the Russian National Research Foundation, project no. 19-18-00300 «Institutes of realization of resource potential of the older generation in the economy of aging».

\section{REFERENCES}

1. Gee E., Gutman G. The overselling of population ageing: apocalyptic demography, intergenerational challenges, and social policy. Oxford, Oxford University Press, 2000. 192 p.

2. Tinker A. The social implications of an ageing population. Mechanisms of Ageing and Development, 2002 , vol. 123, Iss. 7, pp. 729-735. Available at: https://doi.org/10.1016/S0047-6374(01)00418-3 (accessed 10 June 2019).

3. Bengtsson T., Scott K. Population aging and the future of the welfare state: the example of Sweden. Population and Development Review, 2011, vol. 37, pp. 158-170.

4. Lee R. The outlook for population growth. Science, 2011, vol. 333, Iss. 6042, pp. 569-573.

5. Dobrokhleb V.G. Russian population ageing: regional aspect. Territorial Development Issues, 2018, no. 4 (44). DOI: 10.15838/tdi.2018.4.44.4 In Rus.

6. Grigoreva I.A., Sizova I.L., Vidyasova L.A., Dmitrieva A.V., Parfenova O.A., Petukhova I.S. Stareniya bolshe ne budet [There will be no more aging]. St. Petersburg, Asterion Publ., 2018. 136 p.

7. Palomba R., Kotowska I., Kotowska I.E. The economically active population in Europe. Strasbourg, Council of Europe, 2003. 126 p.

8. Vishnevskaya N.T. Older Workers in the OECD Labour. Ekonomicheskiy zhurnal Vysshey shkoly ekonomiki, 2017, vol. 21, no. 4, pp. 680-701. In Rus.

9. Shulgin S.G., Zinkina Yu.V., Aleshkovsky I.A., Andreev A.I. Problems of development of active ageing: global trends and regional. Vestnik Moskovskogo universiteta. Seriya 27 “Globalistika i geopolitika”, 2018, no. 4, pp. 55-68. In Rus.

10. Rittel H.W.J., Webber M.M. Dilemmas in a general theory of planning. Policy Science, 1973, vol. 4, pp. $155-169$.

11. Akoff R. Planirovanie budushchego korporatsii [Planning for the future of the corporation]. Moscow, Progress Publ., 1985. 327 p.

12. Kleyner G.B. «Myagkie» $\mathrm{i}$ «zhestkie2 sistemy v ekonomike [«Soft» and «hard» systems in the economy]. XVII Mezhdunarodnaya konferentsiya. Sistemnaya ekonomika, ekonomicheskaya kibernetika, myagkie izmereniya [Systemic economics, economic cybernetics, soft measurements. XVII International Conference]. St. Petersburg, SPbGETU «LETI» Publ., 2014. pp. 6-12.

13. Zub A.T., Loktionov M.V. Strategicheskiy menedzhment: sistemny podkhod [Strategic management: systemic approach]. Moscow, Genezis Publ., 2011. 848 p.

14. Gumennikov I.V., Monastyrny E.A. Kompleksnoe modelirovanie sotsialno-ekonomicheskikh protsessov i sistem. Myagkiy sistemny analiz [Comprehensive modeling of socio-economic processes and systems. Soft system analysis]. Sbornik nauchnykh trudov V Mezhdunarodnoy nauchnoy konferentsii. Informatsionnye tekhnologii $v$ nauke, upravlenii, sotsialnoy sfere $i$ meditsine Ch. 2 [Information technologies in science, management, social sphere and medicine: collection of scientific papers of the $\mathrm{V}$ International scientific conference. P. 2.]. Tomsk, TPU Publ., 2018. pp. 437-443.

15. Monastyrny E.A., Kasinskiy S.V., Dyrko N.P., Kotova V.V. Realizatsiya potentsiala starshego pokoleniya: statistika zanyatosti (na primere Sibirskogo federalnogo okruga i Tomskoy oblasti) [Realization of the potential of the older generation: employment statistics (on the example of the Siberian Federal District and Tomsk Region]. Materialy Vserossiiskoy konferentsii. Novye tendentsii v deyatelnosti sotsiozashchitnykh institutov [New trends in the activities of social protection institutions: materials of the All-Russian Conference]. Irkutsk, Baykal State University Publ., 2019. pp. 24-29.

16. Monastyrny E.A. Resursny potencial starshego pokoleniya $\mathrm{v}$ zerkale ofitsialnoy statistiki na primere Tomskoy oblasti [The resource potential of the older generation in the mirror of official statistics on the example of the Tomsk region]. Sbornik nauchnykh trudov VI Mezhdunarodnoy konferentsii. 
Informatsionnye tekhnologii $v$ nauke, upravlenii, sotsialnoy sfere $i$ meditsine [Information technologies in science, management, social sphere and medicine: collection of scientific papers of the VI International Conference]. Tomsk, TPU Publ., 2019. pp. 570-572.

17. Federalnaya sluzhba gosudarstvennoy statistiki Rossii [Federal State Statistics Service of Russia]. Available at: https://www.gks.ru/ (accessed 10 May 2019).

18. Starshee pokolenie [Older generation]. Federalnaya sluzhba gosudarstvennoy statistiki Rossii [Federal State Statistics Service of Russia]. Available at: https://www.gks.ru/folder/13877 (accessed 10 May 2019).

19. Edinaya mezhvedomstvennaya informatsionno-statisticheskaya sistema [A single interdepartmental information and statistical system]. Available at: https://fedstat.ru/ (accessed 10 May 2019).

20. Territorialny organ Federalnoy sluzhby gosudarstvennoy statistiki po Tomskoy oblasti [Territorial authority of the Federal State Statistics Service for the Tomsk Region]. Available at: https://tmsk.gks.ru/ (accessed 10 May 2019).

21. Starshee pokolenie Tomskoy oblasti. 2015: analiticheskaya zapiska [The older generation of the Tomsk region. 2015: analytical note]. Tomsk, Tomskstat Publ., 2015. 14 p.

22. Starshee pokolenie Tomskoy oblasti. 2016: analiticheskaya zapiska [The older generation of the Tomsk region. 2016: analytical note]. Tomsk, Tomskstat Publ., 2016. 14 p.

23. Starshee pokolenie Tomskoy oblasti: demografiya i uchastie na rynke truda: analiticheskaya zapiska [The older generation of the Tomsk region: demography and participation in the labor market: analytical note]. Tomsk: Tomskstat Publ., 2019. 18 p.

24. Kasati F., Barysheva G.A., Monastyrny E.A., Ivankina L.I., Pavlova I.A., Shinkeev M.L., Spitsin V.V., Pankova N.M., Gumennikov I.V. Sotsialno-ekonomicheskaya statistika blagopoluchiya starshego pokoleniya [Socio-economic statistics of the well-being of the older generation]. Tomsk, TPU Publ., 2016. 264 p.

Received: 13 June 2019. 